\title{
Effects of dense phase carbon dioxide treatments on color and texture of fresh-cut bitter gourd
}

\author{
ZHANG Chao ${ }^{1, a}$, SUN Xin ${ }^{1,2, b}$, Ma Yue ${ }^{1, c}$, ZHAO Xiao-yan ${ }^{1, d}$,
}

${ }^{1}$ Beijing Vegetable Research Center, Beijing Academy of Agriculture and Forestry Sciences; Beijing Key Laboratory of Fruits and Vegetable Storage and Processing; Key Laboratory of Biology and Genetic Improvement of Horticultural Crops (North China), Ministry of Agriculture; Key Laboratory of Urban Agriculture (North), Ministry of Agriculture, 50 Zhanghua Road, Haidian District, Beijing, 100097

${ }^{2}$ Shenyang Agricultural University, College of Food Science and Engineering, Shenyang, 110161

azhangchao@nercv.org, bsunxin@nercv.org, 'mayue@nercv.org, 'zhaoxiaoyan@nercv.org,

Keywords: dense phase carbon dioxide; time; fresh-cut bitter gourd; cell structure; bitterness

Abstract. The effect of the dense phase carbon dioxide (DPCD), sodium hypochlorite and blanching treatments on the color and texture of the fresh-cut bitter gourd was compared. The DPCD hold the shape and microstructure of the fresh-cut bitter gourd, and reduced their bitterness. The time of the DPCD treatment showed no significant influence on the bitterness reduction. However, the DPCD treatments reduced the greenness of the fresh-cut bitter gourd due to the dissolution of the chlorophyll. Differently, the hypochlorite treatment hold the greenness of the fresh-cut bitter gourd, but showed no influence on their bitterness. Hence, the DPCD and hypochlorite treatment should be selected based on the purpose.

\section{Introduction}

Fresh-cut bitter gourds are made from the fresh bitter gourd, which include the selecting, washing, cutting, pasteurizing, and packaging ${ }^{[1,2]}$. The bitter gourd has shown healthcare function, such as the detoxification, lowering blood sugar and blood fat, antibacterial and antitumor ${ }^{[3,4]}$. Hence, the fresh-cut bitter gourd is becoming more and more popular.

Dense phase carbon dioxide (DPCD) is a non-thermal pasteurization method. The DPCD affects microorganisms, enzymes and the structure of cells through molecular effects of $\mathrm{CO}_{2}{ }^{[5]}$. The DPCD process has been applied to many different fields of food processing ${ }^{[6]}$. The DPCD treatment has increased the pasteurized efficiency of fresh-cut carrot ${ }^{[7]}$ and cocoyam, sweet potato ${ }^{[8]}$. On the other side, DPCD process also lead to the browning, color degradation and texture deteriorating ${ }^{[9]}$.

However, the studies about the information of the DPCD process on fresh-cut bitter gourd are not found to the best of our knowledge according to previous studies.

Hence, the effect of the time of the DPCD treatment on the color and texture of the fresh-cut bitter gourd was evaluated with the blanching and sodium hypochlorite treatments as a control.

\section{Materials and Methods}

Preparation of Fresh-cut Bitter Gourd. Bitter gourds were from a local fruit and vegetable market in Haidian District, Beijing, China. The gourd was stored at $4{ }^{\circ} \mathrm{C}$ for $24 \mathrm{~h}$. And then the fruits were washed by the running tap water to remove the surface contamination, and stirred at $800 \mathrm{rpm}$ for 10 min. The drained fruits was sliced to $4 \mathrm{~mm}$ thickness and removed the seeds. And then the cut fruits were subjected to the heat blanching, Sodium hypochlorite, and DPCD treatment,respectively.

Control: the cut fruits was nominated as the control.

Blanching treatment: the fruits were heated as $52^{\circ} \mathrm{C}$ for $2 \mathrm{~min}$ in a water bath(Stable Temp Co., Ltd., COLE-PARMER, USA). And then the fruits were cooled to $4{ }^{\circ} \mathrm{C}$ in icy water. 
Sodium hypochlorite treatment: the fruits were immersed in a $100 \mathrm{ppm}$ solution of sodium hypochlorite for $2 \mathrm{~min}$ and then rinsed with icy water to reach the temperature of $4{ }^{\circ} \mathrm{C}$. And then the fruits were centrifuged at $800 \mathrm{rpm}$ for $10 \mathrm{~min}$ to remove excess water.

DPCD treatment: The discontinuous DPCD treatment apparatus was manufactured by Haian Co.Ltd., China. The system consisted of a $1 \mathrm{~L}$ stainless steel pressure vessel, temperature controllers, pressure gages and two plunger-type pumps. The system pressure was controlled by a back-pressure regulator and indicated by pointer manometers. An electrical heating jacket was placed around the vessel. Another thermocouple, connected to a temperature controller, was to control and maintain a constant temperature ${ }^{[10]}$. The pressure and temperature were controlled to an accuracy of $\pm 0.4 \mathrm{MPa}$ and $\pm 0.5^{\circ} \mathrm{C}$, respectively. The fruits was subjected the DPCD treatment of $6 \mathrm{MPa}$ for 2 and $10 \mathrm{~min}$ respectively. The temperature of the pressure vessel was hold in $25^{\circ} \mathrm{C}$ with an accuracy of $\pm 0.5^{\circ} \mathrm{C}$ during the whole process. Depressurization of $\mathrm{CO}_{2}$ occurred in less than $10 \mathrm{~min}^{[11]}$.

After the blanching, Sodium hypochlorite, and DPCD treatments, the fruit was packaged for every $200 \mathrm{~g}$ in polyethylene films.

Determination of Chlorophyll Content. To measure the chlorophyll content, $20 \mathrm{~mL}$ of $80 \%$ acetone was added to $5 \mathrm{~g}$ of each sample and mixed with a homogenizer (IKA T10 Basic, Werke $\mathrm{GmbH} \& \mathrm{Co}$. KG, Staufen, Germany) for $1 \mathrm{~min}$ at a high speed, then centrifuged at 8,000 rpm for 5 min at $4{ }^{\circ} \mathrm{C}$, and then filtered through Whatman No.1 filter papers. The volume was adjusted to $25 \mathrm{~mL}$ and the absorbance values were measured at 663 and $645 \mathrm{~nm}$ by spectrophotometer ${ }^{[12]}$ (UV-1800, Shimadzu Corporation, Kyoto, Japan). The chlorophyll content of the sample was calculated followed by Equation 1:

$$
\text { Chlorophyll }=\frac{\left(20.2 \times A_{645}+8.02 \times A_{663}\right) \times D}{1000}
$$

where chlorophyll content is $\mathrm{mg} / \mathrm{g}$ fresh weight; $A_{645}$ and $A_{663}$ are the absorbance at $645 \mathrm{~nm}$ and 663 $\mathrm{nm}$, respectively; $D$ is the dilution factor of the sample.

SEM. The morphological of the fruits were observed by using a SEM. The samples were fixed with aluminum tape and then coated with gold palladium and observed using a scanning electron microscope.

Bitterness Evaluation. The bitterness of the fruits were evaluated by 7 trained panelists. The bitterness level of the fruits was classified by a five-class scheme ( 0 was unacceptable and 5 achieved the best $)^{[13]}$.

Statistical Analysis. Analysis of variance (ANOVA) was used to compare mean differences of the results. If the differences in mean existed, multiple comparisons were performed using Duncan's Multiple Range Test. All analysis was conducted using SPSS for Window Version 19. All experiments were done in triplicates or more.

\section{Results and Discussion}

Effect of DPCD Treatment on Color of Fresh-cut Bitter Gourd. The profiles of the fresh-cut bitter gourd is shown in Fig. 1. The shape of each treated bitter gourd was similar to that of the control. The greenness of the blanching and hypochlorite were similar to that of the control, while that of the DPCD for 2 and 10 min was lighter than that of the control. The greenness of the DPCD of 2 min was stronger than that of the DPCD of 10 min. Hence, the DPCD hold the shape but reduced the greenness of the fresh-cut bitter gourd. 


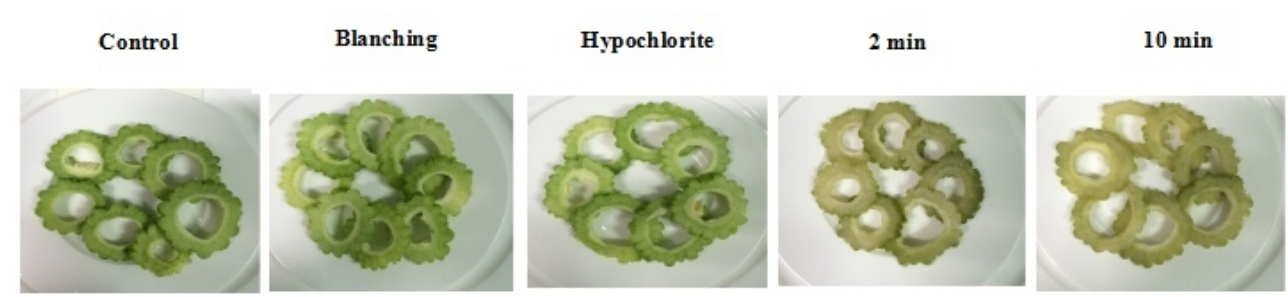

Fig. 1 Profiles of the DPCD treatments

Effect of DPCD Treatment on Chlorophyll Content of Fresh-cut Bitter Gourd. The effect of DPCD treatments on the chlorophyll content of the fresh-cut bitter gourd is shown in Fig. 2. The initial chlorophyll content of the fresh-cut bitter gourd was $3.6 \mathrm{mg} / 100 \mathrm{~g}$. The chlorophyll content of the hypochlorite was similar to that of the control, while that of the Blanching and DPCD treatments was lower than that of the control significantly. Specifically, Blanching reduced $29 \%$ of chlorophyll content. The loss rate of the chlorophyll content was $58 \%$ and $70 \%$ for the DPCD treatments for 2 and $10 \mathrm{~min}$, respectively. This phenomenon could be explained that the DPCD treatments destroy the cell of the bitter gourd, and the inclusions such as the chlorophyll ran out ${ }^{[14,15]}$.

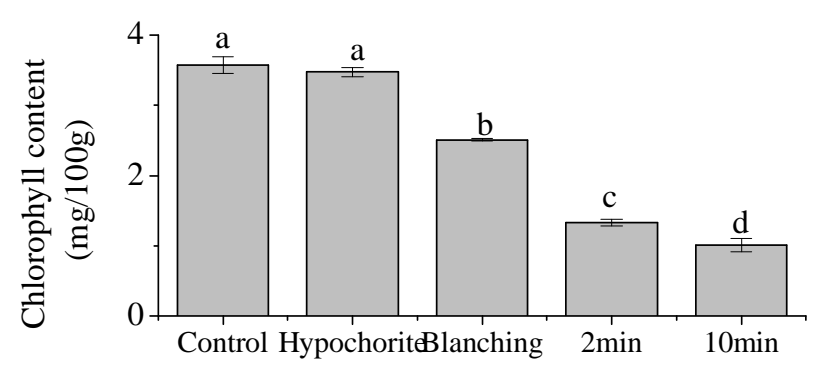

Fig. 2 Effect of DPCD treatments on chlorophyll content of the fresh-cut bitter gourd

Effect of DPCD Treatment on Microstructure of Fresh-cut Bitter Gourd. The SEM profiles present the microstructure of the fresh-cut bitter gourd (Fig. 3). The control presented a complete and smooth cell structure. The DPCD hold the cell structure with a little deformation and some small hole, while the structure of hypochlorite and blanching were fracture and indistinct. The small hole could help to explained the degradation of the chlorophyll.
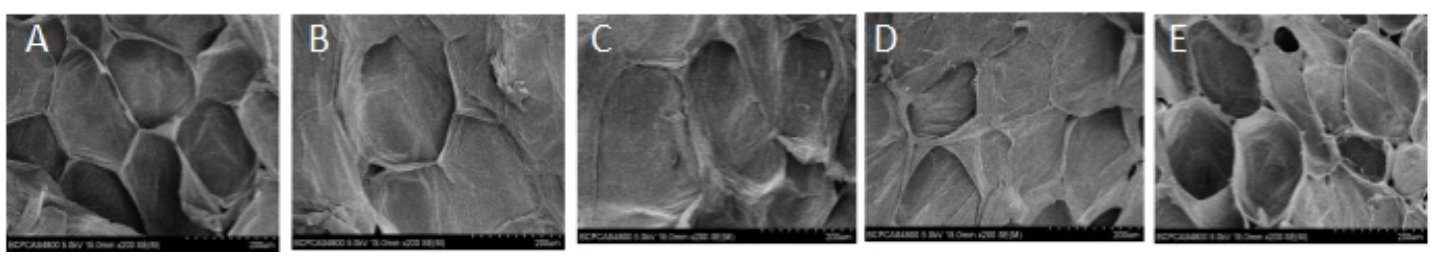

Fig. 3 Effect of DPCD treatments on the microstructure of the Control (A), Blanching (B), Hypochlorite (C), DPCD 2 min (D) and DPCD $10 \min (\mathrm{E})$

Effect of DPCD Treatment on Bitterness of Fresh-cut Bitter Gourd. The bitterness of the bitter gourd is contributed by the dissolution of terpene ${ }^{[16]}$ which is not popular to every consumers. The Blanching and DPCD treatment reduced the bitterness of the fresh-cut bitter gourd significantly comparing to the control, while the hypochlorite hold the original flavor of the bitter gourd. The time of the DPCD showed no influence on the bitterness of the fresh-cut bitter gourd. 


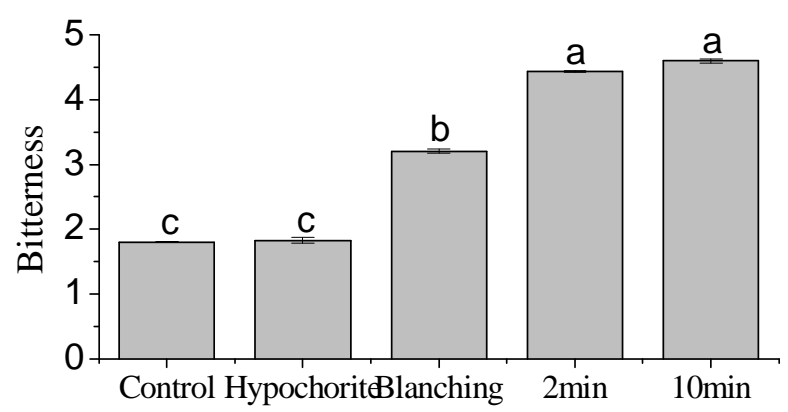

Fig. 4 Effect of DPCD treatments on bitterness of fresh-cut bitter gourd, 1 day

\section{Conclusions}

The DPCD hold the shape and microstructure of the fresh-cut bitter gourd, reduced their bitterness. The time of the DPCD treatment showed no significant influence on the bitterness reduction. However, the DPCD treatments reduced the greenness of the fresh-cut bitter gourd due to the dissolution of the chlorophyll. Being different, the hypochlorite hold the greenness of the fresh-cut bitter gourd, but showed no influence on their bitterness. Hence, the DPCD and hypochlorite treatment should be selected based on the purpose.

\section{References}

[1] C. Chervin and P. Boisseau: J. Food. Sci. Vol. 35-40 (1994), p. 103

[2] D.I. Gabriela, V.R. Sergio and P. Gustavo: LWT-Food. Sci. Technol. Vol. 801-806 (2015), p. 62

[3] J.K. Grover and S.P. Yadav: J. Ethnopharmacol. Sci. Vol. 125-133 (2004), p. 15

[4] C.L. Kalra and J.S. Pruthi: INDIAN. Food. Pucker. Vol. 334-337 (1983), p. 83

[5] S. Sara, D. Komes and V. Aleksandra: J. Supercrit. Fluids. Sci. Vol. $92-100$ (2013), p. 79

[6] B.O. Murat, D. Trang: A. A. Sci. Procedia. Vol. 234-239 (2013), p. 34

[7] G. Ferrentino, N. Calliari: J. Supercrit. Fluids. Sci. Vol. 170-178 (2014), p. 105

[8] O.M. Miguel and DONG Yueqiang: Sci. Tech. Food. Indust. Vol. 290-293 (2013), p.34

[10] O. Garmen and D. Trang: J. Supercrit. Fluids. Sci. Vol. 56-62 (2013), p.82

[11] D. Valverde and M. Iniesta: J. Food. Engin. Vol. 421-428 (2010), p.98

[12] DUAN Guangming: Plant. Physio. Commun. Vol. 221-222 (1992), p.28

[13] G. Jeyasekaran and R.S. Jeya: Food. Microbiol. Vol. 526-533 (2006), p.23

[14] HONG Shan and YUN Yan: Int. J. Food. Microbiol. Vol. 19-28 (2001), p.63

[15] J. Leaseung and L. Seunghwan: Food. Sci. Biotechnol. Vol. 89-95 (2013), p.44

[16] N. Patricia, M. Amanda and G.D. Kwaku: Food. Chem. Vol. 223-227 (2015), p.9 